\title{
Risk Factors, Health Care Resource Utilization, and Costs Associated with Nonadherence to Antiretrovirals in Medicaid-Insured Patients with HIV
}

\author{
Keith Dunn, PharmD, BCPS, AAHIVE; Marie-Hélène Lafeuille, MA; Xiaolong Jiao, MD, MSc; \\ Hela Romdhani, PhD; Bruno Emond, MSc; Kimberly Woodruff, PharmD, PhD; \\ Jacqueline Pesa, MSEd, PhD, MPH; Neeta Tandon, MA; and Patrick Lefebvre, MA
}

\begin{abstract}
BACKGROUND: Adherence to antiretrovirals (ARVs) is critical to achieving durable virologic suppression.

OBJECTIVE: To investigate risk factors of poor adherence and the effect of suboptimal adherence on health care resource utilization (HCRU) and costs in Medicaid patients.

METHODS: A retrospective longitudinal study was conducted using Medicaid data. Adults (aged $\geq 18$ years) with human immunodeficiency virus (HIV)-1 initiating selected ARVs (index date) were identified. Adherence was measured using medication possession ratio (MPR) and proportion of days covered (PDC) at 6 and 12 months post-index. Risk factors of poor adherence (PDC $<80 \%$ ) were assessed using a logistic regression. HCRU and costs were compared between suboptimal $(80 \% \leq \mathrm{PDC}<95 \%)$ and optimal (PDC $\geq 95 \%)$ adherence groups using Poisson and ordinary least square models, respectively.
\end{abstract}

RESULTS: In total, 3,477 patients were identified. Using MPR, 1,282 $(39.0 \%)$ of the evaluable patients had poor adherence; $667(20.2 \%)$ had suboptimal adherence; and 1,342 (40.8\%) had optimal adherence versus 1,342 (51.1\%), 509 (19.0\%), and 804 (30.0\%), respectively, using PDC at 6 months. $\mathrm{PDC}$ at 12 months was even lower. Younger age $(\mathrm{OR}=1.58$; $95 \% \mathrm{Cl}=1.18-2.11 ; P=0.002)$, noncapitated coverage (OR=1.40; $95 \%$ $\mathrm{Cl}=1.16-1.69 ; P<0.001)$, dual Medicaid/Medicare coverage $(\mathrm{OR}=5.98$; $95 \% \mathrm{Cl}=4.39-8.16 ; P<0.001)$, no baseline ARV treatment $(\mathrm{OR}=1.98 ; 95 \%$ $\mathrm{Cl}=1.62-2.41 ; P<0.001)$, and baseline asymptomatic $\mathrm{HIV}(\mathrm{OR}=1.37 ; 95 \%$ $\mathrm{Cl}=1.13-1.68 ; P=0.002)$ were associated with higher risk of poor adherence. Suboptimal adherence patients had higher total number of days spent in a hospital (incidence rate ratio $[\mathrm{IRR}]=1.62 ; 95 \% \mathrm{Cl}=1.13-2.19$; $P=0.008)$, total number of long-term care admissions (IRR $=3.11 ; 95 \%$ $\mathrm{Cl}=1.26-7.39 ; P=0.008$ ), total medical costs (mean monthly cost difference $=\$ 339 ; 95 \% \mathrm{Cl}=\$ 153-\$ 536 ; P<0.001$ ), and inpatient costs (mean monthly cost difference $=\$ 259 ; 95 \% \mathrm{Cl}=\$ 122-\$ 418 ; P<0.001)$ compared with patients with optimal adherence.

CONCLUSIONS: Nonadherence to ARVs was observed in $60 \%-80 \%$ of Medicaid patients, depending on the adherence measure used, and was associated with incremental HCRU and costs. Age, insurance type and coverage, previous ARV treatment, and HIV symptoms were predictors of adherence. Treatment options that enhance adherence and prevent developing virologic failure with drug resistance should be considered for HIV patients.

J Manag Care Spec Pharm. 2018;24(10):1040-51

Copyright @ 2018, Academy of Managed Care Pharmacy. All rights reserved.

\section{What is already known about this subject}

For people with human immunodeficiency virus (HIV), optimal adherence to antiretroviral therapy is critical in maintaining virologic suppression.

Some studies have suggested that adherence to antiretroviral therapy is particularly challenging in low-income populations

\section{What this study adds}

Nonadherence to antiretrovirals was found in a large proportion of Medicaid patients with HIV and was associated with incremental health care resource utilization and costs.

Predictors of adherence included age, insurance type and coverage, previous antiretroviral treatment, and HIV symptoms.

T $\mathrm{n}$ the United States, the Centers for Disease Control and Prevention estimates that more than 1.2 million people had human immunodeficiency virus (HIV) infection in 2016. ${ }^{1}$ HIV is treated using antiretroviral (ARV) therapy, which typically combines 3 or more ARVs to prevent HIV replication and disease progression and reduce the risk of transmission. ARV therapy does not cure HIV infection but can increase patients' survival and improve quality of life., ${ }^{2,3}$ With the success of highly active ARV therapy in decreasing mortality and morbidity, HIV has transitioned from being a terminal condition to a chronic condition that is managed over a longer period of time. This has resulted in an increase in the number of patients with HIV in the United States and, recently, a decrease in the number of new cases. ${ }^{4}$

In some patients with HIV, ARV therapy does not lead to sustained suppression of HIV replication. This situation is called virologic failure and usually results, if mutations develop, in a switch to a second-line therapy. 5,6 Several factors may be responsible for virologic failure, such as drugs' barrier to resistance, ${ }^{7,8}$ drug-food interactions, and drug-drug interactions with concomitant medications. ${ }^{9}$ Optimal adherence to ARVs is also critical to achieving and maintaining virologic suppression and preventing the development of resistance and, thus, to improving overall health, quality of life, and survival 
in patients with HIV.-10 While in many disease areas an adherence level of $80 \%$ is considered a reasonable cut-off point that stratifies adherent and nonadherent patients, in patients with HIV, adherence to ARV therapy $\geq 95 \%$ is usually considered necessary for optimal ARV efficacy. ${ }^{11-13}$

Some studies have suggested adherence to ARV therapy varies in different patient populations and is particularly challenging in low-income populations. ${ }^{14-16}$ The purpose of this study was to evaluate adherence to ARV treatment, assess the risk factors of poor adherence, and compare health care resource utilization (HCRU) and health care costs between patients with suboptimal versus optimal adherence among Medicaid-insured patients with HIV initiating commonly used ARVs.

\section{Methods}

\section{Data Sources}

Medicaid databases from 6 states (Iowa: 2Q 2012-1Q 2015; Kansas: 2Q 2012-1Q 2015; New Jersey: 2Q 2012-1Q 2014; Missouri: 2Q 2012-1Q 2015; Mississippi: 2Q 2012-1Q 2015; and Wisconsin: 2Q 2012-4Q 2013) were available for use in this study. Medicaid databases contain information on medical claims (e.g., type of service; service unit; date; International Classification of Diseases, Ninth Revision, Clinical Modification [ICD-9-CM]; Current Procedural Terminology, 4th Edition, codes; physician specialty; and type of provider); prescription drug claims (e.g., days supply, service date, and National Drug Code numbers); and eligibility (e.g., age, gender, enrollment start/end dates, and date/year of death). All data collected were de-identified in compliance with the patient confidentiality requirements of the Health Insurance Portability and Accountability Act. ${ }^{17}$

\section{Study Design and Patient Selection}

A retrospective longitudinal study was conducted to achieve the study objectives. For the purpose of this study, the most commonly used ARVs at the beginning of the study period (November 2012) were considered: darunavir $800 \mathrm{mg}$, atazanavir $300 \mathrm{mg}$, elvitegravir $150 \mathrm{mg}$, and efavirenz $600 \mathrm{mg}$ (all once-daily), and raltegravir $400 \mathrm{mg}$ twice-daily. The index date was defined as the date of the first claim of one of the ARVs of interest during the study period. Agents had to be taken as part of an ARV regimen. Darunavir $800 \mathrm{mg}$ and atazanavir $300 \mathrm{mg}$ had to be administered in combination with $\geq 1$ boosting agent (ritonavir or cobicistat). All ARV regimens had to be administered with $\geq 2$ different nucleoside reverse transcriptase inhibitors (NRTIs) within 14 days; elvitegravir 150 mg had to be administered as part of the 1-pill combination elvitegravir/cobicistat/emtricitabine/tenofovir disoproxil fumarate (Stribild), which includes 2 NRTIs and 1 boosting agent.

Patients included in this study were aged $\geq 18$ years, had $\geq 6$ months of continuous enrollment pre-index, and had $\geq 1$ diagnosis for HIV-1 (ICD-9-CM codes 042 and V08) with no other dosage of the index ARV during the 6-month pre-index (baseline) period. These patients could have been naive to ARVs or treatment experienced. Patients diagnosed with HIV-2 during the baseline period were excluded.

Patients were observed from the index date to either the end of eligibility (e.g., disenrollment, loss of follow-up, or death) or the end of data availability (March 2015), whichever occurred first.

\section{Outcome Measures and Statistical Analysis}

Demographic and clinical characteristics were assessed during the baseline period and included age, gender, race, region characteristics, insurance eligibility, year of index date, ARV medication use (excluding boosting agents), HIV symptoms (ICD9-CM code 042), and Charlson Comorbidity Index (CCI) ${ }^{18}$ as well as most prevalent comorbidities (any mental comorbidity excluding substance-related and addictive disorders, hypertension, substance-related and addictive disorders, psychoses, chronic pulmonary disease, and diabetes). ${ }^{19,20}$ Baseline total allcause medical costs and all-cause medical costs for each type of visit (outpatient, inpatient, emergency room, long-term care, home care, and other visits) were reported.

Treatment patterns assessed during the observation period included the number of claims for any ARV (not limited to the agents used in the population selection, excluding boosting agents); the proportion of patients with $\geq 2$ claims for any ARV; and time on ARV treatment, defined as the period between the first observed pharmacy claim for any ARV and the end of the last observed pharmacy claim (based on the days supply) for any ARV.

The proportion of patients with $\geq 1$ or $\geq 2$ observed gaps of $\geq 30$ and $\geq 60$ days in treatment with any ARV (not limited to the agents used in the population selection, excluding boosting agents) was assessed during the observation period and reported along with the average gap length per patient. A gap was defined as the period between the end of a pharmacy claim and the start of the following pharmacy claim for any ARV. It was calculated for patients with $\geq 2$ claims for any ARV.

Adherence to any ARV (not limited to the agents used in the population selections, excluding boosting agents) was assessed during the observation period and included medication possession ratio (MPR) and proportion of days covered (PDC) at 6 and 12 months post-index, calculated among patients with $\geq 6$ and $\geq 12$ months of observation period, respectively. MPR was defined as the number of nonoverlapping days supply of any ARV post-index, divided by the time on treatment (in days). PDC was defined as the sum of nonoverlapping days supply of any ARV during a fixed period of time, divided by the length of the period. MPR was calculated for patients with $\geq 2$ claims of any ARV. Patients were classified into 3 adherence groups based on MPR and on PDC independently: poor adherence (adherence $<80 \%$ ), suboptimal adherence (adherence between $80 \%$ and $95 \%$ ), and optimal adherence (adherence $\geq 95 \%$ ). ${ }^{11,21}$ Patients were considered to be adherent to ARV treatment even if they changed ARV regimen. 
Risk Factors, Health Care Resource Utilization, and Costs Associated with Nonadherence to Antiretrovirals in Medicaid-Insured Patients with HIV

TABLE 1 Baseline Demographic and Clinical Characteristics

\begin{tabular}{|c|c|c|c|}
\hline & $\begin{array}{l}\text { ARV Patients } \\
(\mathrm{N}=3,477)\end{array}$ & & $\begin{array}{l}\text { ARV Patients } \\
(\mathrm{N}=3,477)\end{array}$ \\
\hline \multicolumn{2}{|l|}{ Demographic characteristics ${ }^{a}$} & \multicolumn{2}{|l|}{ Year of index date, n (\%) } \\
\hline Age, years, mean \pm SD [median] & $44.9 \pm 10.9[46.3]$ & 2012 & $206 \quad(5.9)$ \\
\hline \multicolumn{2}{|l|}{ Age categories, years, n (\%) } & 2013 & $2,353(67.7)$ \\
\hline $18-24$ & $185 \quad(5.3)$ & 2014 & $778(22.4)$ \\
\hline $25-34$ & $533(15.3)$ & 2015 & $140 \quad(4.0)$ \\
\hline $35-44$ & $862(24.8)$ & \multicolumn{2}{|l|}{ Clinical characteristics $^{b}$} \\
\hline $45-54$ & $1,281(36.8)$ & \multicolumn{2}{|l|}{ ARV agent taken on the index date, $\mathrm{n}(\%)$} \\
\hline$\geq 55$ & $616(17.7)$ & Efavirenz & $1,101(31.7)$ \\
\hline Male, n (\%) & $2,055(59.1)$ & Elvitegravir & $664(19.1)$ \\
\hline \multicolumn{2}{|l|}{ Race, n (\%) } & Atazanavir & $596(17.1)$ \\
\hline White & $998(28.7)$ & Raltegravir & $587(16.9)$ \\
\hline Black & $1,938(55.7)$ & Darunavir & $580(16.7)$ \\
\hline Hispanic & $28 \quad(0.8)$ & No baseline ARV medication use, ${ }^{\mathrm{c}} \mathrm{n}(\%)$ & $2,557(73.5)$ \\
\hline Other & $300(8.6)$ & HIV symptoms ${ }^{\mathrm{d}}$ & $2,182(62.8)$ \\
\hline Unknown & $213 \quad(6.1)$ & $\mathrm{CCI}$ (excluding HIV symptoms), mean \pm SD [median] & $0.6 \pm 1.2 \quad[0.0]$ \\
\hline \multicolumn{2}{|l|}{ State, n (\%) } & \multicolumn{2}{|l|}{ Comorbidities } \\
\hline Iowa & $283(8.1)$ & $\begin{array}{l}\text { Any mental comorbidity excluding substance- } \\
\text { related and addictive disorders }\end{array}$ & $1,050(30.2)$ \\
\hline Kansas & $99(2.8)$ & Hypertension & $742(21.3)$ \\
\hline Mississippi & $393(11.3)$ & Substance-related and addictive disorders & $622(17.9)$ \\
\hline Missouri & $1,205(34.7)$ & Psychoses & $537(15.4)$ \\
\hline New Jersey & $1,316(37.8)$ & Chronic pulmonary disease & $510(14.7)$ \\
\hline Wisconsin & $181 \quad(5.2)$ & Diabetes & $305 \quad(8.8)$ \\
\hline \multicolumn{2}{|l|}{ Region characteristics, n (\%) } & \multicolumn{2}{|l|}{ Health care costs ${ }^{b}$} \\
\hline Urban & $2,275(65.4)$ & $\begin{array}{l}\text { Monthly all-cause medical costs, }{ }^{\mathrm{e}} \\
\text { mean } \pm \text { SD [median] }\end{array}$ & $706 \pm 2,106 \quad[46]$ \\
\hline Suburban & $767(22.1)$ & Outpatient visits & $124 \pm 318 \quad[15]$ \\
\hline Rural & $435(12.5)$ & Emergency room visits & $15 \pm 54 \quad[0]$ \\
\hline \multicolumn{2}{|l|}{ Insurance eligibility, n (\%) } & Inpatient visits & $380 \pm 1,806 \quad[0]$ \\
\hline Capitated or dual Medicaid/Medicare coverage & $2,136(61.4)$ & Long-term care admission & $25 \pm 415 \quad[0]$ \\
\hline Capitated & $1,755(50.5)$ & Home care & $67 \pm 392 \quad[0]$ \\
\hline Dual Medicaid/Medicare coverage & $553(15.9)$ & Other & $96 \pm 414 \quad[0]$ \\
\hline
\end{tabular}

${ }^{a}$ Assessed at the index date.

${ }^{b}$ Assessed within the 6-month baseline period.

'The count excluded the boosting agents (ritonavir and cobicistat).

dPresence of HIV symptoms was identified using the ICD-9-CM code 042.

¿2015 U.S. dollars.

$A R V=$ antiretroviral; $C C I=$ Charlson Comorbidity Index; HIV=human immunodeficiency virus; ICD-9-CM=International Classification of Diseases, Ninth Revision, Clinical Modification; $S D=$ standard deviation

Descriptive statistics were used to report baseline characteristics, treatment patterns, and adherence outcomes. Means, standard deviations (SDs), and medians were reported for continuous variables and frequencies and percentages for categorical variables.

First, univariable logistic regression models were used to assess risk factors of poor adherence according to PDC at 6 and 12 months using odds ratios (ORs). The following potential risk factors of poor adherence were considered: age, gender, race, region, year of index date, no capitated insurance eligibility (plans where providers are paid a fixed amount per enrollee to cover a defined scope of services), and dual Medicaid/
Medicare coverage eligibility, each evaluated at index; and CCI score, baseline ARV medication use (excluding boosting agents), the most prevalent comorbidities, and HIV symptoms, each evaluated during the baseline period. Second, a multivariable regression model including all the considered risk factors was performed and ORs were reported.

Monthly HCRU and health care costs were evaluated over the observation period and reported for each type of visit (outpatient, emergency room, inpatient, long-term care, home care, and other visits). All costs represent the amount paid by Medicaid and were expressed in constant 2015 U.S. dollars using the medical care component of the Consumer Price 
Index. ${ }^{22}$ Monthly HCRU and health care costs were compared between patients with optimal (PDC $\geq 95 \%$ ) and suboptimal $(80 \% \leq \mathrm{PDC}<95 \%)$ adherence using PDC at 6 and 12 months. Patients with PDC $<80 \%$ were excluded from this analysis due to likely different HCRU patterns and baseline characteristics than patients with suboptimal adherence.

To minimize the effect of potential confounding factors without reducing the size of the study population, inverse probability of treatment weighting (IPTW), which controls for differences in baseline characteristics between the 2 cohorts, was used. The IPTW was defined as the inverse of the probability of having suboptimal or optimal adherence, based on a multivariable logistic regression model conditional on the baseline covariates. After weighting, the baseline characteristics were compared between the 2 groups using standardized differences. Characteristics with standardized differences $<10 \%$ were considered balanced. ${ }^{23}$

HCRU incidence rate ratios (IRRs) and the mean monthly cost differences (MMCDs) between the 2 weighted groups were estimated using Poisson and ordinary least square models, respectively. Given the nonnormal distribution of the HCRU and costs, comparison tests were conducted for the IRRs and MMCDs using 95\% confidence intervals (CIs) and $P$ values, both estimated using a nonparametric bootstrap resampling method with 499 replications. ${ }^{24} P$ values $<0.05$ were considered statistically significant. Only patients with an observation period of $\geq 6$ and $\geq 12$ months were considered for the analysis using PDC at 6 and 12 months, respectively.

\section{Results}

\section{Baseline Characteristics}

A total of 3,477 patients was included in the study (darunavir [ $\mathrm{n}=580$ ], atazanavir [ $\mathrm{n}=596]$, raltegravir [ $\mathrm{n}=587$ ], elvitegravir [n=664], efavirenz $[n=1,101])$. Of note, drug subgroups were not mutually exclusive because a patient could be initiated on 2 or more of these drugs simultaneously.

Baseline characteristics are presented in Table 1. The mean age was 44.9 years $(\mathrm{SD}=10.9$; median $=46.3)$. Among the selected patients, $59.1 \%$ were male, $55.7 \%$ were black, $65.4 \%$ were living in an urban area, $62.8 \%$ had HIV symptoms, and 26.5\% were previously treated with ARVs during the baseline period. At baseline, the most prevalent comorbidity noted was any mental comorbidity (excluding substance-related and addictive disorders), present in $30.2 \%$ of the study population. Additionally, other frequently observed baseline comorbidities included hypertension (21.3\%), substance-related and addictive disorders (17.9\%), psychoses (15.4\%), chronic pulmonary disease (14.7\%), and diabetes (8.8\%). The mean monthly health care medical cost during the baseline period was $\$ 706$ $(\mathrm{SD}=\$ 2,106$; median $=\$ 46)$, mainly driven by inpatient visit costs (mean $=\$ 380 ; \mathrm{SD}=\$ 1,806$; median $=\$ 0$ ).

\section{TABLE 2 Treatment Patterns and Adherence} During the Observation Period ${ }^{a}$

\begin{tabular}{|c|c|c|}
\hline & \multicolumn{2}{|c|}{$\begin{array}{l}\text { ARV Patients } \\
(\mathrm{N}=3,477)\end{array}$} \\
\hline Observation period, days, mean \pm SD [median] & \multicolumn{2}{|c|}{$386.5 \pm 235.0[366.0]$} \\
\hline$\geq 6$ months, $\mathrm{n}(\%)$ & 2,683 & $(77.2)$ \\
\hline$\geq 12$ months, $\mathrm{n}(\%)$ & 1,780 & $(51.2)$ \\
\hline Number of claims of any ARV, mean \pm SD [median] & $14.2 \pm 14.2$ & {$[10.0]$} \\
\hline Patients with $\geq 2$ claims of any ARV, $n(\%)$ & 3,291 & $(94.7)$ \\
\hline $\begin{array}{l}\text { Time on treatment }{ }^{\mathrm{b}} \text { for any ARV, days, } \\
\text { mean } \pm \text { SD [median] }\end{array}$ & $324.5 \pm 236.7$ & [296.0] \\
\hline \multicolumn{3}{|l|}{ Observed gaps ${ }^{\mathrm{c}}$ of $\geq 30$ days $(\mathrm{n}=3,291)$} \\
\hline$\geq 1$ gap, n (\%) & 1,348 & $(41.0)$ \\
\hline$\geq 2$ gaps, $\mathrm{n}(\%)$ & 555 & (16.9) \\
\hline Average length of gap & $154.4 \pm 118.0$ & [114.0] \\
\hline \multicolumn{3}{|l|}{ Observed gaps ${ }^{\mathrm{c}}$ of $\geq 60$ days $(\mathrm{n}=3,291)$} \\
\hline$\geq 1$ gap, $\mathrm{n}(\%)$ & 1,014 & $(30.8)$ \\
\hline$\geq 2$ gaps, $\mathrm{n}(\%)$ & 364 & $(11.1)$ \\
\hline Average length of gap per patient, mean \pm SD [me & $199.9 \pm 110.7$ & [188.5] \\
\hline MPR, ${ }^{\mathrm{d}}$ mean \pm SD [median] $(\mathrm{n}=3,291)$ & $0.78 \pm 0.26$ & [0.90] \\
\hline Poor adherence (MPR < 80\%), n (\%) & 1,282 & $(39.0)$ \\
\hline Suboptimal adherence $(80 \% \leq$ MPR $<95 \%), \mathrm{n}(\%)$ & 667 & $(20.2)$ \\
\hline Optimal adherence (MPR $\geq 95 \%), \mathrm{n}(\%)$ & 1,342 & $(40.8)$ \\
\hline PDC, $\mathrm{f}$ at 6 months, mean \pm SD [median] $(\mathrm{n}=2,683)$ & $0.71 \pm 0.27$ & [0.79] \\
\hline Poor adherence (PDC< $80 \%), \mathrm{n}(\%)$ & 1,370 & $(51.0)$ \\
\hline Suboptimal adherence $(80 \% \leq \mathrm{PDC}<95 \%), \mathrm{n}(\%)$ & 509 & $(19.0)$ \\
\hline Optimal adherence (PDC $\geq 95 \%), \mathrm{n}(\%)$ & 804 & $(30.0)$ \\
\hline PDC ${ }^{\mathrm{e}, \mathrm{g}}$ at 12 months, mean \pm SD [median] $(\mathrm{n}=1,780)$ & $0.58 \pm 0.31$ & [0.58] \\
\hline Poor adherence (PDC<80\%), n (\%) & 1,176 & $(66.1)$ \\
\hline Suboptimal adherence $(80 \% \leq \mathrm{PDC}<95 \%), \mathrm{n}(\%)$ & 298 & $(16.7)$ \\
\hline Optimal adherence (PDC $\geq 95 \%), \mathrm{n}(\%)$ & 306 & $(17.2)$ \\
\hline
\end{tabular}

aAll counts excluded boosting agents (ritonavir and cobicistat).

${ }^{b}$ Time on treatment was defined as the number of days between the first fill and the last refill plus the days supply of the last refill.

cA gap was defined as a period of time between the end of a prescription and the following claim of any ARV and was calculated over the entire observation period for patients with $\geq 2$ ARV claims.

${ }^{d}$ MPR was defined as the number of nonoverlapping days supply of any ARV during the follow-up period divided by the time on treatment. It was calculated for patients with $\geq 2$ ARV claims.

${ }^{e} P D C$ was defined as the sum of nonoverlapping days supply of any ARV during a fixed period of time divided by the length of the period.

${ }^{f}$ Calculated for patients with $\geq 6$ months of observation period. gCalculated for patients with $\geq 12$ months of observation period. $A R V=$ antiretroviral $P D C=$ proportion of days covered; $M P R=$ medication posses sion ratio; $S D=$ standard deviation.

\section{Treatment Patterns}

Table 2 presents the treatment patterns and adherence during the observation period. The mean length of the observation period post-index was 386.5 days $(S D=235.0$; median $=366.0)$, and $2,683(77.2 \%)$ and $1,780(51.2 \%)$ patients had $\geq 6$ and $\geq 12$ months of observation period, respectively. The mean number of claims for any ARV was $14.2(\mathrm{SD}=14.2$; median=10.0). Mean time on treatment was $324.5(S D=236.7$; median $=296.0)$ days with $1,348(41.0 \%)$ patients with $\geq 1$ gap of $\geq 30$ days in ARV treatment and 1,014 (30.8\%) with $\geq 1$ gap of $\geq 60$ days. 
Risk Factors, Health Care Resource Utilization, and Costs Associated with Nonadherence to Antiretrovirals in Medicaid-Insured Patients with HIV

\begin{tabular}{|c|c|c|c|c|c|c|c|c|}
\hline \multirow[b]{3}{*}{ Potential Risk Factors of Poor Adherence } & \multicolumn{8}{|c|}{$\begin{array}{l}\text { Poor Adherence Based on PDC at } 6 \text { Months } \\
\qquad \begin{array}{c}\text { PDC }<80 \%{ }^{a} \\
(n=2,683)\end{array}\end{array}$} \\
\hline & \multirow{2}{*}{$\begin{array}{c}\mathrm{PDC}<80 \% \\
(\mathrm{n}=1,370) \\
\mathrm{n}(\%)\end{array}$} & \multirow{2}{*}{$\begin{array}{c}\text { PDC } \geq 80 \% \\
(\mathrm{n}=1,313) \\
\mathrm{n}(\%)\end{array}$} & \multicolumn{3}{|c|}{ Univariable Logistic Model } & \multicolumn{3}{|c|}{ Multivariable Logistic Model ${ }^{b}$} \\
\hline & & & OR & $(95 \% \mathrm{CI})$ & $P$ Value & OR & $(95 \% \mathrm{CI})$ & $P$ Value \\
\hline \multicolumn{9}{|l|}{ Age categories, years (reference: $\geq 50$ years) } \\
\hline $18-29$ & $172(12.6)$ & $131(10.0)$ & 1.27 & $(0.98-1.65)$ & 0.074 & 1.58 & $(1.18-2.11)$ & $0.002^{c}$ \\
\hline $30-49$ & $722(52.7)$ & $722(55.0)$ & 0.97 & $(0.82-1.14)$ & 0.684 & 0.96 & $(0.80-1.16)$ & 0.690 \\
\hline$\geq 50$ & $476(34.7)$ & $460(35.0)$ & 1.00 & - & - & 1.00 & - & - \\
\hline Female (reference: male) & $495(36.1)$ & $564(43.0)$ & 0.75 & $(0.64-0.88)$ & $<0.001^{c}$ & 1.10 & $(0.92-1.32)$ & 0.291 \\
\hline \multicolumn{9}{|l|}{ Race (reference: black) } \\
\hline White & $476(34.7)$ & $318(24.2)$ & 1.57 & $(1.32-1.87)$ & $<0.001^{c}$ & 1.14 & $(0.93-1.40)$ & 0.212 \\
\hline Black & $723(52.8)$ & $758(57.7)$ & 1.00 & - & - & 1.00 & - & - \\
\hline Otherd $^{d}$ & $171(12.5)$ & $237(18.1)$ & 0.76 & $(0.61-0.94)$ & $0.014^{\mathrm{c}}$ & 1.00 & $(0.78-1.28)$ & 0.976 \\
\hline \multicolumn{9}{|l|}{ Region characteristics (reference: suburban/rural) } \\
\hline Suburban/rural & $547(39.9)$ & $394(30.0)$ & 1.00 & - & - & 1.00 & - & - \\
\hline Urban & $823(60.1)$ & $919(70.0)$ & 0.65 & $(0.55-0.76)$ & $<0.001^{\mathrm{c}}$ & 1.00 & $(0.81-1.24)$ & 0.995 \\
\hline No capitated insurance eligibility & $795(58.0)$ & $582(44.3)$ & 1.74 & $(1.49-2.02)$ & $<0.001^{\mathrm{c}}$ & 1.40 & $(1.16-1.69)$ & $<0.001^{\mathrm{c}}$ \\
\hline Dual coverage insurance eligibility & $392(28.6)$ & $69 \quad(5.3)$ & 7.22 & $(5.52-9.46)$ & $<0.001^{\mathrm{c}}$ & 5.98 & $(4.39-8.16)$ & $<0.001^{\mathrm{c}}$ \\
\hline \multicolumn{9}{|l|}{ Year of index date (reference: 2014 or after) } \\
\hline Before 2014 & $1,071(78.2)$ & $1,067(81.3)$ & 0.83 & $(0.68-1.00)$ & $0.047^{\mathrm{c}}$ & 1.20 & $(0.96-1.51)$ & 0.117 \\
\hline 2014 or after & $299(21.8)$ & $246(18.7)$ & 1.00 & - & - & 1.00 & $(1.00-1.00)$ & - \\
\hline No prior ARV medication use ${ }^{f, g}$ & $1,129(82.4)$ & $862(65.7)$ & 2.45 & $(2.05-2.93)$ & $<0.001^{c}$ & 1.98 & $(1.62-2.41)$ & $<0.001^{\mathrm{c}}$ \\
\hline \multicolumn{9}{|l|}{ CCI score (excluding HIV symptoms) f } \\
\hline 0 & $948(69.2)$ & $863(65.7)$ & 1.33 & $(0.98-1.80)$ & 0.063 & 1.12 & $(0.71-1.78)$ & 0.624 \\
\hline 1 & $238(17.4)$ & $219(16.7)$ & 1.32 & $(0.94-1.85)$ & 0.113 & 1.03 & $(0.68-1.55)$ & 0.887 \\
\hline 2 & $99 \quad(7.2)$ & $128 \quad(9.7)$ & 0.94 & $(0.64-1.38)$ & 0.744 & 0.76 & $(0.48-1.20)$ & 0.240 \\
\hline$\geq 3$ & $85 \quad(6.2)$ & $103(7.8)$ & 1.00 & - & - & 1.00 & - & - \\
\hline \multicolumn{9}{|l|}{ Comorbidities } \\
\hline Chronic pulmonary disease & $191(13.9)$ & $217(16.5)$ & 0.82 & $(0.66-1.01)$ & 0.063 & 1.17 & $(0.86-1.61)$ & 0.323 \\
\hline Diabetes & $124 \quad(9.1)$ & $122 \quad(9.3)$ & 0.97 & $(0.75-1.26)$ & 0.829 & 1.18 & $(0.83-1.68)$ & 0.358 \\
\hline Hypertension & $274(20.0)$ & $297(22.6)$ & 0.86 & $(0.71-1.03)$ & 0.098 & 1.02 & $(0.80-1.30)$ & 0.877 \\
\hline Psychoses & $216(15.8)$ & $210(16.0)$ & 0.98 & $(0.80-1.21)$ & 0.872 & 0.96 & $(0.72-1.28)$ & 0.768 \\
\hline Substance-related and addictive disorders & $219(16.0)$ & $259(19.7)$ & 0.77 & $(0.64-0.94)$ & $0.012^{\mathrm{c}}$ & 1.12 & $(0.89-1.43)$ & 0.336 \\
\hline $\begin{array}{l}\text { Any mental comorbidity excluding substance-related } \\
\text { and addictive disorders }\end{array}$ & $384(28.0)$ & $413(31.5)$ & 0.85 & $(0.72-1.00)$ & 0.052 & 0.92 & $(0.72-1.17)$ & 0.485 \\
\hline No HIV symptoms ${ }^{\mathrm{f}, \mathrm{h}}$ & $493(36.0)$ & $433(33.0)$ & 1.14 & $(0.97-1.34)$ & 0.102 & 1.37 & $(1.13-1.68)$ & $0.002^{\mathrm{c}}$ \\
\hline
\end{tabular}

ancludes patients with $\geq 6$ months of observation period.

${ }^{b}$ The states were included in the model as a controlling factor.

Indicates that $P<0.05$.

Includes Hispanic, other, and unknown races.

eRefers to insurance coverage by both Medicaid and Medicare.

fAssessed within the 6-month baseline period.

gThe count excluded boosting agents (ritonavir and cobicistat).

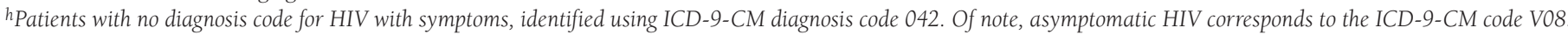
$A R V=$ antiretroviral; $C C I=$ Charlson Comorbidity Index; CI= confidence interval; HIV=human immunodeficiency virus; ICD-9-CM=International Classification of Diseases, Ninth Revision, Clinical Modification; OR=odds ratio; PDC=proportion of days covered.

Mean MPR was $0.78(\mathrm{SD}=0.26$; median $=0.90 ; \mathrm{n}=3,291)$. Based on MPR, $39.0 \%, 20.2 \%$, and $40.8 \%$ of patients had poor, suboptimal, and optimal adherence to ARVs, respectively. Average PDC was $0.71(\mathrm{SD}=0.27$; median $=0.79 ; \mathrm{n}=2,683)$ at 6 months and 0.58 ( $\mathrm{SD}=0.31$; median $=0.58 ; \mathrm{n}=1,780)$ at 12 months. Using PDC at 6 months, $51.0 \%, 19.0 \%$, and $30.0 \%$ of patients had poor, suboptimal, and optimal adherence to ARVs, respectively, versus $66.1 \%, 16.7 \%$, and $17.2 \%$, respectively, using PDC at 12 months.

\section{Risk Factors of Poor Adherence}

Assessing adherence using PDC at 6 months, the following factors were found to be associated with significantly higher 


\section{Months}

Health Care Resource Utilization

Outpatient visits

Emergency room visits

Inpatient visits

Total number of days spent in a hospital Long-term care admission

Total number of days with long-term care Home care

Other

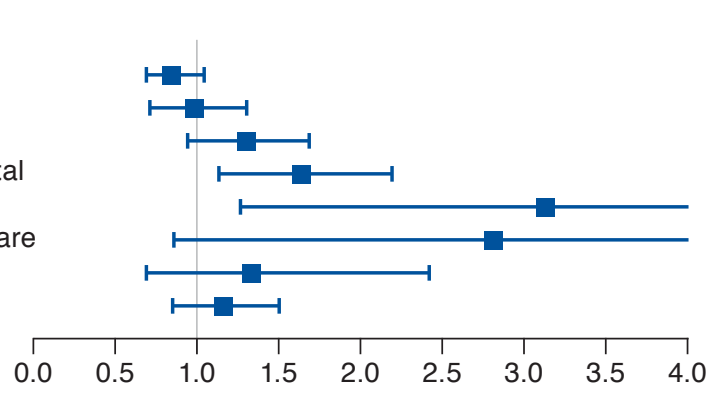

All-Cause Medical Costs

Outpatient visits

Emergency room visits

Inpatient visits

Long-term care admission

Home care

Other

$\begin{array}{cc}\text { IRR }^{\text {b }} & \text { (95\% Cl) } \\ 0.84 & (0.68,1.05) \\ 0.97 & (0.71,1.30) \\ 1.29 & (0.94,1.69) \\ 1.62 & (1.13,2.19)^{\mathrm{C}} \\ 3.11 & (1.26,7.39)^{\mathrm{c}} \\ 2.80 & (0.85,9.46) \\ 1.33 & (0.67,2.41) \\ 1.16 & (0.85,1.50)\end{array}$

\begin{tabular}{|c|c|}
\hline $\begin{array}{l}\text { Mean } \\
\text { Cost }\end{array}$ & $\begin{array}{l}\text { lonthly } \\
\text { fference }{ }^{\mathrm{d}, \mathrm{e}}\end{array}$ \\
\hline 339 & $(153,536)^{c}$ \\
\hline 1 & $(-28,33)$ \\
\hline 0 & $(-4,3)$ \\
\hline 259 & $(122,418)^{c}$ \\
\hline 43 & $(-34,125)$ \\
\hline 28 & $(-9,65)$ \\
\hline 8 & $(-5,20)$ \\
\hline
\end{tabular}

Less likely/costly for patients More likely/costly for patients with suboptimal adherence with suboptimal adherence

\footnotetext{
a Suboptimal adherence is $80 \% \leq P D C<95 \%$; optimal adherence is $P D C \geq 95 \%$.

${ }^{b}$ Obtained from Poisson regression models with bootstrap procedure.

Indicates that $P<0.05$.

dObtained from ordinary least square regression models with bootstrap procedure.

e2015 U.S. dollars.

$C I=$ confidence interval; $H C R U=$ health care resource utilization; $I R R=$ incident rate ratio; $P D C=$ proportion of days covered.
}

risk of poor adherence in the univariable analysis: white race (vs. black; $\mathrm{OR}=1.57 ; \mathrm{P}<0.001$ ), noncapitated insurance coverage $(\mathrm{OR}=1.74 ; P<0.001)$, dual Medicaid/Medicare coverage $(\mathrm{OR}=7.22 ; P<0.001)$, and no baseline ARV treatment $(\mathrm{OR}=2.45 ; P<0.001 ;$ Table 3). Female $(\mathrm{OR}=0.75 ; P<0.001)$, other races (vs. black; $\mathrm{OR}=0.76 ; P=0.014$ ), urban regions (vs. suburban/urban; $\mathrm{OR}=0.65 ; P<0.001$ ), and earlier index dates (2012-2013 vs. 2014-2015; $O R=0.83 ; P=0.047$ ) were associated with significantly lower risk of poor adherence (Table 3). However, in the multivariable analysis, only younger age (18-29 years vs. $\geq 50$ years; $O R=1.58 ; P=0.002$ ), noncapitated insurance coverage ( $\mathrm{OR}=1.40 ; P<0.001)$, dual Medicaid/ Medicare coverage $(\mathrm{OR}=5.98 ; P<0.001)$, no baseline ARV treatment $(\mathrm{OR}=1.98 ; \mathrm{P}<0.001)$, and baseline asymptomatic HIV (OR=1.37; $P=0.002)$ were associated with significantly higher risk of poor adherence.

Using PDC at 12 months to assess adherence (Appendix A, available in online article), white race (vs. black; $\mathrm{OR}=1.48$; $P<0.001)$, noncapitated insurance coverage $(\mathrm{OR}=1.26$;
$P=0.021)$, dual Medicaid/Medicare coverage $(\mathrm{OR}=13.42$; $P<0.001)$, no prior ARV treatment during baseline period $(\mathrm{OR}=2.20 ; P<0.001)$, and lower CCI scores ( 0 and 1 vs. 3 or more; $\mathrm{OR}=1.69$ and $P=0.010$ for $\mathrm{CCI}$ score $0 ; \mathrm{OR}=1.57$ and $P=0.046$ for CCI score 1) were found to be associated with significantly higher risk of poor adherence in the univariable analysis. Females $(\mathrm{OR}=0.73 ; P=0.002)$ and substance-related and addictive disorders $(\mathrm{OR}=0.75 ; P=0.031)$ were associated with decreased risk of poor adherence. In the multivariable analysis, only dual Medicaid/Medicare coverage $(\mathrm{OR}=14.35$; $P<0.001)$, no baseline ARV treatment $(\mathrm{OR}=1.73 ; P<0.001)$, and baseline asymptomatic HIV $(\mathrm{OR}=1.48 ; P=0.003)$ were associated with a significantly higher risk of poor adherence.

\section{Comparison of HCRU and Health Care Costs Between Patients with Suboptimal Versus Optimal Adherence}

To control for potential differences in baseline characteristics between patients with optimal and suboptimal adherence, IPTW was used. After weighting, most characteristics for 
the 2 groups were well balanced. Post-IPTW, the effective sample sizes for the optimally (PDC $\geq 95 \%$ ) and suboptimally $(80 \% \leq$ PDC $<95 \%)$ adherent patients were 661 and 652, respectively, at 6 months, and 299 and 305, respectively, at 12 months. Using PDC at 6 months, patients with suboptimal adherence had a significantly higher total number of days spent in a hospital (0.417 days/month) compared with patients with optimal adherence $(0.276$ days/month) with IRR $=1.62$ (95\% CI =1.13-2.19; $\mathrm{P}=0.008$; Figure 1), and more long-term care admissions on average ( 0.003 vs. 0.001 per month) with IRR $=3.11$ (95\% CI=1.26-7.39; $P=0.008$; Figure 1). Patients with suboptimal adherence also had significantly higher mean medical costs (\$763 monthly) compared with patients with optimal adherence ( $\$ 424$ monthly) with $\mathrm{MMCD}=\$ 339$ (95\% CI $=$ $\$ 153-\$ 536 ; P<0.001 ;$ Figure 1). This difference was mainly driven by inpatient visit costs $(\mathrm{MMCD}=\$ 259 ; 95 \% \mathrm{CI}=\$ 122$ $\$ 418 ; P<0.001$; Figure 1).

Using PDC at 12 months to define the adherence groups (Appendix B, available in online article) gave similar results: significantly higher total number of days spent in a hospital (IRR $=1.79 ; 95 \% \mathrm{CI}=1.17-2.70 ; P=0.004)$ and significantly higher mean medical costs (MMCD $=\$ 341 ; 95 \% C I=\$ 70-\$ 584$; $P=0.008)$, also mainly driven by inpatient visits $(\mathrm{MMCD}=\$ 231$; $95 \% \mathrm{CI}=\$ 45-\$ 411 ; P=0.016)$.

\section{Discussion}

This study revealed nonadherence rates of $60 \%$ (MPR) to $80 \%$ (PDC), as well as 30\%-40\% of patients with gaps in ARV treatment among Medicaid-insured patients with HIV initiated on commonly used ARVs, suggesting a large proportion of patients were nonadherent to ARVs.

These findings seem to be more pronounced in this study of Medicaid patients than in other studies of commercially insured patients with HIV. For instance, a study of a commercially insured population revealed that about $75 \%$ of patients with HIV had PDC at 6 months $\geq 80 \%$, and $80 \%$ and $69 \%$ had $\mathrm{MPR} \geq 80 \%$ and $\geq 90 \%$, respectively, ${ }^{15}$ versus only $49 \%$ with PDC at 6 months $\geq 80 \%$, and $61 \%$ and $50 \%$ with MPR $\geq 80 \%$ and $\geq 90 \%$, respectively, in the current study. Our results were, nevertheless, consistent with most reports using Medicaid data.

A previous study on Medicaid patients with HIV showed that mean PDC at 12 months was 0.64 (vs. 0.58 for the current study), with $32 \%$ of patients having PDC $\geq 90 \%$ (vs. $24 \%$ for the current study). ${ }^{25}$ In another study using multistate Medicaid data on HIV-infected adults aged 50-64 years, 32\% of patients had a PDC by combination ARV therapies at 11 months $\geq 95 \% .{ }^{26}$ Using a slightly different adherence definition, the current study found that $17.2 \%$ of patients had PDC $\geq 95 \%$ at 12 months. To our knowledge, only 1 study (by Juday et al., 2013) appears to conflict with our findings on adherence levels, reporting higher optimal adherence rates in different ARV groups using Medicaid data (around 50\% of patients had PDC $\geq 95 \%$ over the entire observation period). ${ }^{27}$
However, in the Juday et al. study, the follow-up period ended when a gap of $\geq 30$ days was observed in the initial therapy. Consequently, no gaps of $\geq 30$ days were included in the period used to assess adherence, potentially inflating it artificially. In contrast, our study identified a significant proportion of patients who experienced gaps of $\geq 30$ days and $\geq 60$ days. These large gaps in treatment are important to consider, as they may more accurately depict real-world adherence to treatment and identify sporadic treatment patterns that could increase the risk of HIV-1 drug resistance.

In the current study, adherence appeared to be higher at 6 months than at 12 months. The proportion of patients with poor adherence was $51.1 \%$ and $66.1 \%$ using PDC at 6 and 12 months, respectively. Risk factors associated with poor adherence also varied based on whether the PDC was evaluated at 6 or at 12 months. While younger age (18-29 vs. $\geq 50$ years), noncapitated insurance coverage, dual Medicaid/Medicare coverage, no baseline ARV use, and baseline asymptomatic HIV were found to be significantly associated with poor adherence using PDC at 6 months, only dual Medicaid/Medicare coverage, no baseline ARV use, and baseline asymptomatic HIV were significantly associated with poor adherence at 12 months. These findings suggest that predicting adherence to ARVs at different time points of treatment could be challenging, and adherence assessments should be conducted continuously throughout treatment.

Our findings confirm some previously documented factors associated with poor adherence. ${ }^{28,29}$ Becker et al. (2002) measured adherence using PDC at 12 months and found that younger HIV-infected adults are at greater risk of poor adherence. ${ }^{30}$ While we could not demonstrate age as a significant predictor of poor adherence using PDC at 12 months, we did note younger age as a significant predictor of poor adherence using PDC at 6 months. This could be attributed to the different analytical methods they used. For example, instead of defining adherence groups as was done in our study, the investigators used continuous PDC and tested the effect of age using an analysis of variance model.

Additionally, our study confirmed the findings of Kong et al. (2012), who studied Medicaid-insured patients with HIV from 2003 to $2007 .{ }^{25}$ These investigators found that depression was not associated with decreasing adherence. Conversely, our findings differ slightly from previous research demonstrating that black race was significantly associated with nonadherence. While we were able to identify black race as a significant predictor of poor adherence in the univariable analysis, this was not the case in the multivariable analysis. This could be partially because of the difference in the study period and the population. Additionally, the ARV regimens examined in Kong's study (lamivudine-, abacavir-, zidovudine-, emtricitabine-, efavirenz-, and lopinavir-based regimens) are very different from those used in the current study. In addition, the variables included in our logistic regression model were different. 
Our study also showed that patients with suboptimal adherence had a higher total number of days spent in a hospital, more long-term care admissions, and higher medical costs compared with patients with optimal adherence. These results are consistent with other studies. For instance, Gardner et al. (2008) found that higher adherence to ARVs was associated with decreased HCRU and costs. ${ }^{31}$ Nachega et al. (2010) further found that higher adherence to ARVs was associated with lower health care costs, in particular, reduced hospitalization costs. ${ }^{32}$

While this study did not examine the relationship between nonadherence and the development of drug resistance, according to DHHS guidelines as well as previous literature, $, 12,13,33,34$ one of the most common causes of virologic failure and development of ARV resistance is suboptimal adherence. Our study showed increased HCRUs and costs associated with nonadherence mainly driven by inpatient visits; however, it was not able to distinctly describe the clinical drivers of these incremental costs. A previous study has shown that ARV-experienced patients with HIV who developed secondary resistance had $22 \%$ higher mean monthly costs than those without resistance (1,291 vs. 1,083 Canadian dollars), leading the authors to hypothesize that increased costs associated with nonadherence may be driven by the development of ARV resistance. ${ }^{35}$

While further research is needed to directly associate nonadherence with added costs attributed to resistance, there are several options available for clinicians that may improve adherence or help prevent the development of resistance. Today, multiple ARVs are being coformulated to allow for convenience and, in many cases, once-daily dosing. Additionally, regimens with higher barriers to resistance should be considered for patients with HIV with high risk of nonadherence. ${ }^{7}$

\section{Limitations}

This study has some limitations. As with all real-world data sources, the Medicaid data used may contain inaccuracies or omissions in diagnoses, billing, and other variables, although this is not expected to be differential between groups. Data from the 6 states may not be generalizable to the overall Medicaid population, other states, or non-Medicaid patients.

In addition, ARV claims were assumed to indicate their use. However, patients might not have adhered to treatment as prescribed. Thus, the adherence assessed in this study may differ from self-reported adherence or actual adherence. Social factors that could affect adherence, such as stigma and family support, are not available in claims data and were not considered as potential risk factors for poor adherence. Moreover, while our current analysis was able to identify some significant predictors of poor adherence, information on the reasons for nonadherence was not available. Additional work should be performed to examine predictors or reasons for the large gaps in treatment that were reported.
Population selection was based on a list of most commonly prescribed ARVs at the beginning of the study period. However, this list could change over time and may not reflect the current practice. Our study was not designed to assess adherence to individual components of ARV regimens, since the treatment guidelines advocate for the combination of ARVs from different classes. ${ }^{9}$ Also, since boosting agents taken alone do not contribute to an effective ARV regimen, and to not artificially inflate the adherence to ARVs, calculation of gaps, MPR, and PDC excluded boosting agents, even though they were part of the ARV regimens used to identify the study population. Nevertheless, regimens that involve boosting agents that are not part of coformulations represent an adherence issue that could compromise the regimen effectiveness if boosting agents were omitted. Therefore, there is risk of overestimating adherence, assuming some patients took some regimens without the accompanied boosting agents.

In this study, an adherence level of $95 \%$ was considered in the definition of optimal adherence. However, some studies, such as FOTO, ${ }^{36}$ allowed 1 group of patients to skip ARV doses over the weekend and revealed noninferior success compared with constant ARV dosing. Given improvements in ARV therapy, including agents with longer half-lives and higher barriers to resistance, consideration may be given to whether previously defined adherence thresholds are still relevant or need to be reexamined.

\section{Conclusions}

Nonadherence to ARVs was observed in a large proportion of Medicaid patients and was associated with incremental HCRU and costs. These findings are of concern, as nonadherence to ARVs remains a significant cause of virologic failure. In addition, age, insurance type and coverage, prior ARV treatment, and symptomatic HIV disease were revealed as predictors of adherence. Clinicians may consider treatment options that may improve adherence and reduce the risk of drug resistance in patients at risk of virologic failure.

\section{Authors}

KEITH DUNN, PharmD, BCPS, AAHIVE; XIAOLONG JIAO, MD, MSc; KIMBERLY WOODRUFF, PharmD, PhD; JACQUELINE PESA, MSEd, PhD, MPH; and NEETA TANDON, MA, Health Economics and Outcomes Research, Janssen Scientific Affairs, Titusville, New Jersey. MARIE-HÉLĖNE LAFEUILLE, MA; HELA ROMDHANI, PhD; BRUNO EMOND, MSc; and PATRICK LEFEBVRE, MA, Groupe d'analyse, Ltée, Montréal, Quebec, Canada.

AUTHOR CORRESPONDENCE: Keith Dunn, PharmD, BCPS, AAHIVE, Janssen Scientific Affairs, 1125 Trenton-Harbourton Rd., Titusville, NJ 08560. Tel.: 860.917.6731; E-mail: kdunn1@its.jnj.com. 


\section{DISCLOSURES}

This study was supported by Janssen Scientific Affairs, which was involved in the study design, data collection, data analysis, manuscript preparation, and publication decisions. Emond, Lafeuille, Romdhani, and Lefebvre are employees of Analysis Group, a consulting company that received research grants from Janssen Scientific Affairs to conduct this study. Dunn, Woodruff, Pesa, and Tandon are current employees and stockholders of Johnson \& Johnson, owner of Janssen Scientific Affairs. Jiao was an employee of Janssen at the time of the study. Emond has received grants from Novartis, Regeneron, Aegerion, Lundbeck, Bristol-Myers Squibb, Bayer, Millennium, Allergan, AbbVie, and GlaxoSmithKline unrelated to this study.

Part of the material in this study was presented at the Academy of Managed Care Pharmacy 2017 Annual Meeting; March 27-30, 2017; Denver, CO, and at the 9th International AIDS Society Conference; July 23-26, 2017; Paris, France.

\section{ACKNOWLEDGMENTS}

Technical editorial assistance was provided by Shannon O'Sullivan, ELS, of MedErgy, and was supported by Janssen Scientific Affairs

\section{REFERENCES}

1. Centers for Disease Control and Prevention. HIV in the United States: at a glance. 2016. Updated November 2017. Available at: http://www.cdc.gov/hiv/ statistics/overview/ataglance.html. Accessed May 14, 2018.

2. Marins JR, Jamal LF, Chen SY, et al. Dramatic improvement in survival among adult Brazilian AIDS patients. AIDS. 2003;17(11):1675-82.

3. Lima VD, Hogg RS, Harrigan PR, et al. Continued improvement in survival among HIV-infected individuals with newer forms of highly active antiretroviral therapy. AIDS. 2007;21(6):685-92.

4. Centers for Disease Control and Prevention. Today's HIV/AIDS epidemic. CDC fact sheet. August 2016. Available at: https://www.cdc.gov/nchhstp/ newsroom/docs/factsheets/todaysepidemic-508.pdf. Accessed May 14, 2018.

5. ART-LINC of IeDEA Study Group, Keiser O, Tweya H, et al. Switching to second-line antiretroviral therapy in resource-limited settings: comparison of programmes with and without viral load monitoring. AIDS. 2009;23(14):1867-74.

6. Günthard HF, Saag MS, Benson CA, et al. Antiretroviral drugs for treatment and prevention of HIV infection in adults: 2016 recommendations of the International Antiviral Society-USA panel. JAMA. 2016;316(2):191-210.

7. Luber AD. Genetic barriers to resistance and impact on clinical response. J Int AIDS Soc. 2005;7(3):69.

8. Friedland GH, Williams A. Attaining higher goals in HIV treatment: the central importance of adherence. AIDS. 1999;13(Suppl 1):S61-72.

9. DHHS Panel on Antiretroviral Guidelines for Adults and Adolescents. Guidelines for the use of antiretroviral agents in adults and adolescents living with HIV. Available at: http://aidsinfo.nih.gov/contentfiles/lvguidelines/ AdultandAdolescentGL.pdf. Accessed May 14, 2018.

10. Carrieri MP, Chesney MA, Spire B, et al. Failure to maintain adherence to HAART in a cohort of French HIV-positive injecting drug users. Int J Behav Med. 2003;10(1):1-14.

11. Paterson DL, Swindells S, Mohr J, et al. Adherence to protease inhibitor therapy and outcomes in patients with HIV infection. Ann Intern Med. 2000;133(1):21-30.

12. Bangsberg DR, Hecht FM, Charlebois ED, et al. Adherence to protease inhibitors, HIV-1 viral load, and development of drug resistance in an indigent population. AIDS. 2000;14(4):357-66.

13. Bangsberg DR, Kroetz DL, Deeks SG. Adherence-resistance relationships to combination HIV antiretroviral therapy. Curr HIV/AIDS Rep. 2007;4(2):65-72.
14. The Menges Group. Prescription drug adherence in Medicaid managed care. Report. October 2014. Available at: https://staticl.squarespace. com/static/589912dflbl0e39bd04eb3ab/t/58acfd39b8a79b6e48e5b fd5/1487732027040/Medication-Adherence-in-Medicaid-Managed-CareFINAL-Reportl.pdf. Accessed May 14, 2018.

15. Forlenza JB, Brown K, Shprecher A, et al. An evaluation of patient characteristics, duration on antiretrovirals (ARVs) and adherence in a large, insured U.S. population receiving HIV treatment between 2010-2014. Poster presented at: Academy of Managed Care Pharmacy Nexus 2015; October 26-29, 2015; Orlando, Florida.

16. Lafeuille MH, Woodruff K, Dunn K, et al. Adherence to antiretrovirals (ARVs) in Medicaid-insured patients living with human immunodeficiency virus (HIV). Poster presented at: Academy of Managed Care Pharmacy 2017 Annual Meeting; March 27-30, 2017; Denver, Colorado.

17. Atchinson BK, Fox DM. The politics of the Health Insurance Portability and Accountability Act. Health Aff (Millwood). 1997;16(3):146-50.

18. Quan H, Sundararajan V, Halfon P, et al. Coding algorithms for defining comorbidities in ICD-9-CM and ICD-10 administrative data. Med Care. 2005;43(11):1130-39.

19. American Psychiatric Association. Diagnostic and Statistical Manual of Mental Disorders (DSM-5). Washington, DC: American Psychiatric Association Publishing; 2013.

20. Elixhauser A, Steiner C, Kruzikas D. Comorbidity software documentation. 2004. HCUP Methods Series Report \#2004-1. ONLINE February 6, 2004. U.S. Agency for Healthcare Research and Quality. Available at: http:// www.hcup-us.ahrq.gov/reports/ComorbiditySoftwareDocumentationFinal. pdf. Accessed May 14, 2018.

21. Karve S, Cleves MA, Helm M, et al. Good and poor adherence: optimal cut-point for adherence measures using administrative claims data. Curr Med Res Opin. 2009;25(9):2303-10.

22. Bureau of Labor Statistics. Consumer Price Index (CPI). Available at: https://www.bls.gov/cpi/data.htm. Accessed May 14, 2018.

23. Austin PC. Using the standardized difference to compare the prevalence of a binary variable between two groups in observational research. Commun Stat-Simul Comput. 2009;38(6):1228-34.

24. Efron B, Tibshirani RJ. An Introduction to the Bootstrap. New York: Chapman \& Hall/CRC; 1994.

25. Kong MC, Nahata MC, Lacombe VA, Seiber EE, Balkrishnan R. Association between race, depression, and antiretroviral therapy adherence in a low-income population with HIV infection. J Gen Intern Med. 2012;27(9):1159-64.

26. Abara WE, Adekeye OA, Xu J, Heiman HJ, Rust G. Correlates of combination antiretroviral adherence among recently diagnosed older HIVinfected adults between 50 and 64 years. AIDS Behav. 2016;20(11):2674-81.

27. Juday TM, Farr AM, Johnston SS, Chu B-C, Hebden T. Antiretroviral adherence among Medicaid-insured HIV patients initiating current guideline-preferred antiretroviral therapy regimens. Paper presented at: ISPOR 2013; May 18-22, 2013; New Orleans, Louisiana. Available at: https://www. ispor.org/News/articles/Aug13/Antiretroviral_Adherence_Among_MedicaidInsured_HIV_Patients.asp. Accessed May 14, 2018.

28. Reynolds NR. Adherence to antiretroviral therapies: state of the science. Curr HIV Res. 2004;2(3):207-14.

29. Chesney M. Factors affecting adherence to antiretroviral therapy. Clin Infect Dis. 2000;30(Suppl 2):S171-76.

30. Becker SL, Dezii CM, Burtcel B, Kawabata H, Hodder S. Young HIVinfected adults are at greater risk for medication nonadherence. MedGenMed. 2002;4(3):21.

31. Gardner EM, Maravi ME, Rietmeijer C, Davidson AJ, Burman WJ. The association of adherence to antiretroviral therapy with healthcare utilization and costs for medical care. Appl Health Econ Health Policy. 2008;6(2-3):145-55. 
Risk Factors, Health Care Resource Utilization, and Costs Associated with Nonadherence to Antiretrovirals in Medicaid-Insured Patients with HIV

32. Nachega JB, Leisegang R, Bishai D, et al. Association of antiretroviral therapy adherence and health care costs. Ann Intern Med. 2010;152(1):18-25.

33. Bangsberg D, Acosta EP, Gupta R, et al. Adherence-resistance relationships for protease and non-nucleoside reverse transcriptase inhibitors explained by virological fitness. AIDS. 2006;20(2):223-31.

34. Tam LW, Chui CK, Brumme CJ, et al. The relationship between resistance and adherence in drug-naive individuals initiating HAART is specific to individual drug classes. J Acquir Immune Defic Syndr. 2008;49(3):266-71.
35. Krentz HB, Ko K, Beckthold B, Gill MJ. The cost of antiretroviral drug resistance in HIV-positive patients. Antivir Ther. 2014;19(4):341-48.

36. Cohen CJ, Colson AE, Sheble-Hall AG, McLaughlin KA, Morse GD. Pilot study of a novel short-cycle antiretroviral treatment interruption strategy: 48-week results of the five-days-on, two-days-off (FOTO) study. HIV Clin Trials. 2007;8(1):19-23. 
Risk Factors, Health Care Resource Utilization, and Costs Associated with Nonadherence to Antiretrovirals in Medicaid-Insured Patients with HIV

\section{APPENDIX A Risk Factors of Poor Adherence (Based on the PDC at 12 Months) Using a Logistic} Regression Model

\begin{tabular}{|c|c|c|c|c|c|c|c|c|}
\hline \multirow[b]{3}{*}{ Potential Risk Factors of Low Adherence } & \multicolumn{8}{|c|}{$\begin{array}{l}\text { Low Adherence Based on PDC at } 12 \text { Months } \\
\qquad \begin{array}{l}\text { PDC }<80 \% \text { a } \\
(n=1,780)\end{array}\end{array}$} \\
\hline & \multirow{2}{*}{\begin{tabular}{|c}
$\begin{array}{c}\text { PDC }<80 \% \\
(\mathrm{n}=1,176)\end{array}$ \\
$\mathrm{n}(\%)$ \\
\end{tabular}} & \multirow{2}{*}{$\begin{array}{c}\mathrm{PDC} \geq 80 \% \\
(\mathrm{n}=604)\end{array}$} & \multicolumn{3}{|c|}{ Univariable Logistic Model } & \multicolumn{3}{|c|}{ Multivariable Logistic Model ${ }^{\mathrm{b}}$} \\
\hline & & & OR & $(95 \% \mathrm{CI})$ & $P$ Value & OR & $(95 \% \mathrm{CI})$ & $P$ Value \\
\hline \multicolumn{9}{|l|}{ Age categories, years (reference: $\geq 50$ years) } \\
\hline $18-29$ & $123(10.5)$ & $63(10.4)$ & 1.00 & $(0.71-1.42)$ & 0.990 & 1.45 & $(0.99-2.11)$ & 0.057 \\
\hline $30-49$ & $640(54.4)$ & $329(54.5)$ & 1.00 & $(0.81-1.23)$ & 0.989 & 1.09 & $(0.86-1.39)$ & 0.483 \\
\hline$\geq 50$ & $413(35.1)$ & $212(35.1)$ & 1.00 & - & - & 1.00 & - & - \\
\hline Female (reference: male) & $392(33.3)$ & $246(40.7)$ & 0.73 & $(0.59-0.89)$ & $0.002^{\mathrm{c}}$ & 1.04 & $(0.83-1.31)$ & 0.744 \\
\hline \multicolumn{9}{|l|}{ Race (reference: black) } \\
\hline White & $438 \quad(37.2)$ & $167(27.6)$ & 1.48 & $(1.18-1.85)$ & $<0.001^{\mathrm{c}}$ & 1.05 & $(0.81-1.38)$ & 0.697 \\
\hline Black & $599(50.9)$ & $338(56.0)$ & 1.00 & - & - & 1.00 & $(1.00-1.00)$ & - \\
\hline Otherd & $139(11.8)$ & $99(16.4)$ & 0.79 & $(0.59-1.06)$ & 0.116 & 1.00 & $(0.72-1.39)$ & 0.978 \\
\hline \multicolumn{9}{|l|}{ Region characteristics (reference: suburban/rural) } \\
\hline Suburban/rural & $472(40.1)$ & $222(36.8)$ & 1.00 & - & - & 1.00 & - & - \\
\hline Urban & $704(59.9)$ & $382(63.2)$ & 0.87 & $(0.71-1.06)$ & 0.166 & 1.15 & $(0.88-1.51)$ & 0.300 \\
\hline No capitated insurance eligibility ${ }^{\mathrm{e}}$ & $671(57.1)$ & $310(51.3)$ & 1.26 & $(1.03-1.53)$ & $0.021^{\mathrm{c}}$ & 0.90 & $(0.70-1.16)$ & 0.402 \\
\hline Dual Medicaid/Medicare coverage insurance eligibility & $396(33.7)$ & $22 \quad(3.6)$ & 13.42 & $(8.62-20.90)$ & $<0.001^{\mathrm{c}}$ & 14.35 & $(8.90-23.16)$ & $<0.001^{\mathrm{c}}$ \\
\hline \multicolumn{9}{|l|}{ Year of index date (reference: 2014 or after) } \\
\hline Before 2014 & $956(81.3)$ & $501(82.9)$ & 0.89 & $(0.69-1.16)$ & 0.391 & 1.06 & $(0.77-1.47)$ & 0.720 \\
\hline 2014 or after & $220(18.7)$ & $103(17.1)$ & 1.00 & - & - & 1.00 & - & - \\
\hline No prior ARV medication use $e^{f, g}$ & $973(82.7)$ & $414(68.5)$ & 2.20 & $(1.75-2.77)$ & $<0.001^{\mathrm{c}}$ & 1.73 & $(1.34-2.23)$ & $<0.001^{\mathrm{c}}$ \\
\hline \multicolumn{9}{|l|}{ CCI score (excluding HIV symptoms) ${ }^{\mathrm{f}}$} \\
\hline 0 & $813(69.1)$ & $394(65.2)$ & 1.69 & $(1.13-2.50)$ & $0.010^{c}$ & 1.41 & $(0.78-2.55)$ & 0.258 \\
\hline 1 & $204(17.3)$ & $106(17.5)$ & 1.57 & $(1.01-2.45)$ & $0.046^{c}$ & 1.22 & $(0.71-2.10)$ & 0.469 \\
\hline 2 & $99 \quad(8.4)$ & $55 \quad(9.1)$ & 1.47 & $(0.89-2.43)$ & 0.132 & 1.22 & $(0.67-2.22)$ & 0.507 \\
\hline$\geq 3$ & $60 \quad(5.1)$ & $49 \quad(8.1)$ & 1.00 & - & - & 1.00 & - & - \\
\hline \multicolumn{9}{|l|}{ Comorbidities } \\
\hline Chronic pulmonary disease & $151(12.8)$ & $96(15.9)$ & 0.78 & $(0.59-1.03)$ & 0.078 & 1.05 & $(0.70-1.56)$ & 0.827 \\
\hline Diabetes & $100 \quad(8.5)$ & $60 \quad(9.9)$ & 0.84 & $(0.60-1.18)$ & 0.318 & 0.90 & $(0.57-1.43)$ & 0.663 \\
\hline Hypertension & $227(19.3)$ & $130(21.5)$ & 0.87 & $(0.68-1.11)$ & 0.268 & 0.95 & $(0.69-1.30)$ & 0.730 \\
\hline Psychoses & $173(14.7)$ & $99(16.4)$ & 0.88 & $(0.67-1.15)$ & 0.351 & 0.81 & $(0.55-1.18)$ & 0.269 \\
\hline Substance-related and addictive disorders & $182(15.5)$ & $118(19.5)$ & 0.75 & $(0.58-0.97)$ & $0.031^{\mathrm{c}}$ & 1.04 & $(0.76-1.41)$ & 0.824 \\
\hline $\begin{array}{l}\text { Any mental comorbidity excluding substance-related and } \\
\text { addictive disorders }\end{array}$ & $313(26.6)$ & $181(30.0)$ & 0.85 & $(0.68-1.05)$ & 0.135 & 0.93 & $(0.68-1.27)$ & 0.652 \\
\hline No HIV symptoms ${ }^{\mathrm{h}}$ & $409(34.8)$ & $198(32.8)$ & 1.09 & $(0.89-1.35)$ & 0.400 & 1.48 & $(1.14-1.91)$ & $0.003^{\mathrm{c}}$ \\
\hline
\end{tabular}

ancludes patients with $\geq 6$ months of observation period.

${ }^{b}$ The states were included in the model as a controlling factor.

Indicates that $\mathrm{P}<0.05$.

dIncludes Hispanic, other, and unknown races.

${ }^{e}$ Refers to insurance coverage by both Medicaid and Medicare.

fAssessed within the 6-month baseline period.

sThe count excluded the boosting agents (ritonavir and cobicistat).

hPatients with no diagnosis code for HIV with symptoms, identified using ICD-9-CM diagnosis code 042. Of note, asymptomatic HIV corresponds to the ICD-9-CM code V08. $A R V=$ antiretroviral; $C C I=$ Charlson Comorbidity Index; $C I=$ confidence interval; HIV = human immunodeficiency virus; ICD-9-CM = International Classification of Diseases, Ninth Revision, Clinical Modification; $O R=$ odds ratio; $P D C=$ proportion of days covered. 
Risk Factors, Health Care Resource Utilization, and Costs Associated with Nonadherence to Antiretrovirals in Medicaid-Insured Patients with HIV

APPENDIX B Comparison of Monthly HCRU and Associated Costs During the Observation Period Between Patients with Suboptimal Versus Optimal Adherence Based on PDC at 12 Months $(n=1,780)$

12 Months

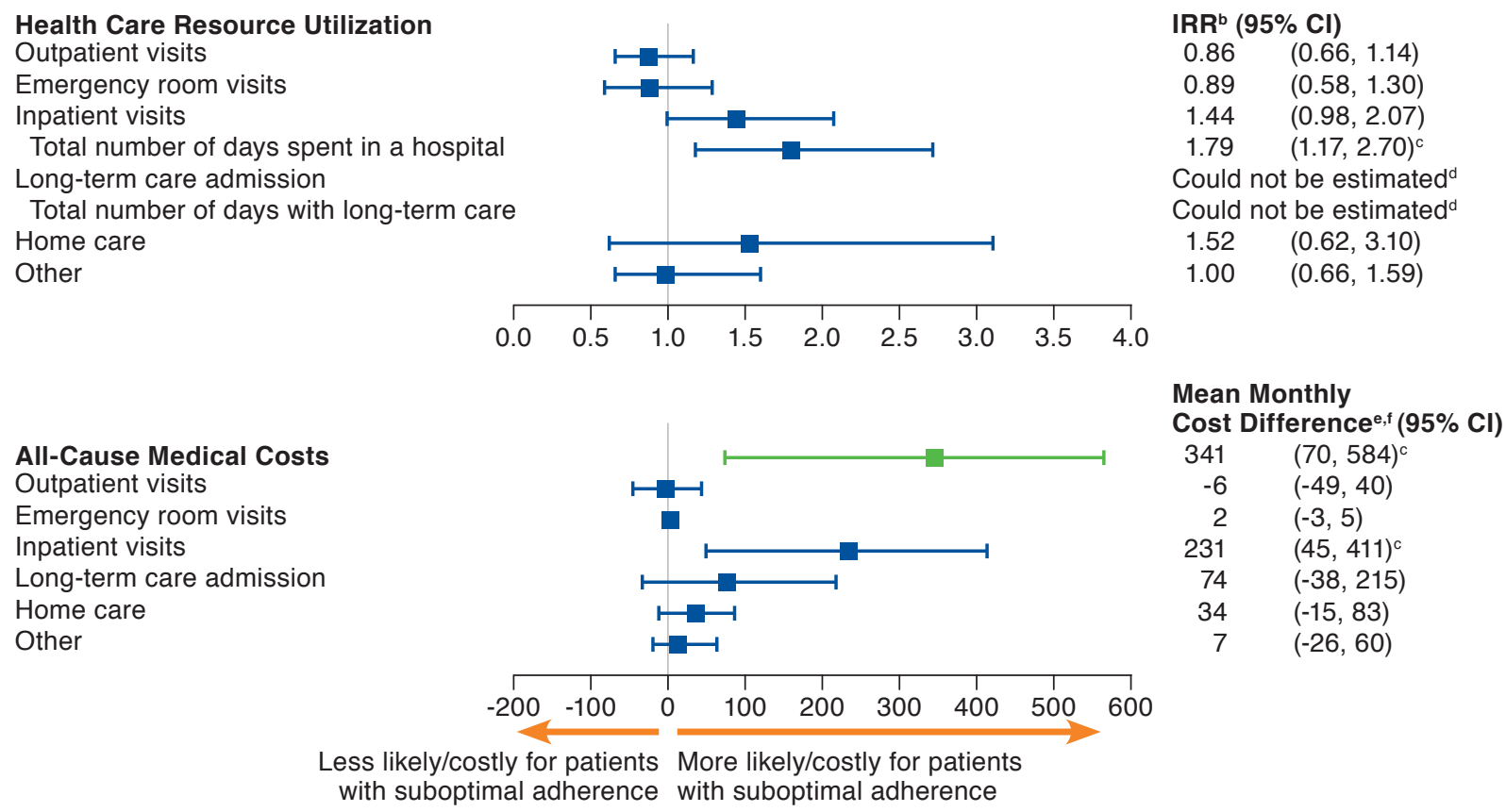

a Suboptimal adherence is $80 \% \leq P D C<95 \%$; optimal adherence is PDC $\geq 95 \%$.

bobtained from Poisson regression models with bootstrap procedure.

cIndicates that $P<0.05$.

dThese values could not be estimated because of insufficient sample size.

'Obtained from ordinary least square regression models with bootstrap procedure.

f2015 U.S. dollars.

$C I=$ confidence interval; $H C R U=$ health care resource utilization; IRR=incident rate ratio; $P D C=$ proportion of days covered. 